\title{
Achieving the Visual Perception and Gestalt Psychology in Sultan Hassan Mosque Building
}

\author{
Essam Metwally \\ Department of Interior Design, Faculty of Architecture and Design, American University of Madaba, Amman, Jordan \\ Email: esammet@yahoo.com
}

How to cite this paper: Metwally, E. (2021) Achieving the Visual Perception and Gestalt Psychology in Sultan Hassan Mosque Building. Open Journal of Applied Sciences, 11, 21-40.

https://doi.org/10.4236/ojapps.2021.111003

Received: December 16, 2020

Accepted: January 15, 2021

Published: January 18, 2021

Copyright () 2021 by author(s) and Scientific Research Publishing Inc. This work is licensed under the Creative Commons Attribution International License (CC BY 4.0)

http://creativecommons.org/licenses/by/4.0/

\begin{abstract}
The gestalt principles are perception and what is visually communicated by objects. These principles describe the visual language within which we work. Understanding how a designer realizes things visually will help designers communicate better. Many designers use Gestalt principles to have a structure visual stimulus, so as to create interfaces that are easy for users to understand. Because the understanding of visual perception is a critical item in any designer's toolkit. Islamic heritage buildings also contain many architectural values, especially the Sultan Hassan Mosque in Cairo. Through this paper, we will verify the use of gestalt principles of visual perception in the building design. Because the psychological organization of the design, achieves the understanding and awareness of the current relationships between the elements, depending on the extent of regularity, accuracy, and consistency of the design elements. This makes us recognize the esthetic values of Sultan Hassan's building and mosque. The visual delight we get from architecture begins with how we perceive it. So, in order to understand how visual delight arises, we must first understand how we perceive and interpret visual stimuli. Especially since the principles of gestalt confirm that the human brain tends to make tricks and illusions. Therefore, we found the mosque designer had exploited this fact during the design process, to exclude any possibility of the resulting misunderstanding. The designer achieved the psychological preparation of the visitor by using some principles of visual perception of the Gestalt theory, such as growth, continuity, and hierarchy.
\end{abstract}

\section{Keywords}

Gestalt Principles, Visual Perception, Psychological Organization, Esthetic Values, Islamic Heritage Buildings

\section{Introduction}

The function of Islamic art was not to transmit the visual but to show what was 
invisible and try to feel the geometric laws governing this universe. To confirm these values, Islamic art has been directed toward engineering and abstraction, depending on symmetry, interchange and multiple spaces in its allocation, line rhythm, and a sense of visual pleasure.

In order for the designer to express the spiritual content of faith in the form of visual values, he must be able to find a way to achieve the goal of art. It was not just creative decorative facets, but it was targeted at content and concept. The intrinsic value inherent in Islamic art is its rhythm, abstraction, and the accompanying sense of music.

Sultan Hassan Mosque is one of the most important archeological mosques in Cairo. It is described as the jewel of Islamic architecture in the east, and is considered the most harmonious Islamic building in Cairo, and represents the maturity of Mamluk architecture. The designer used in the decoration of the building many methods and various architectural elements.

The artist and architect have found a rich field to show his engineering and artistic ability, such as the contrast between closed surfaces and openings, toning in architectural formation, engineering formations, abstraction, repetition, variety, and rhythm. The facades took on a new character and became more luxurious.

Gestalt theory can play an important role in highlighting the value of these architectural styles, and it helps designers to think about the architectural design of heritage buildings in a new way. Many of the principles that come from Gestalt theory can be applied to architectural and decorative works to produce harmonious and complete art and carry a lot of aesthetic values.

The Gestalt principles are very basic to all designs, and a gestalt architect can use these Gestalt principles to help define and highlight his requirement of focal points or to shape our interpretation of his building. But sometimes, we see buildings where Gestalt principles are used, and we discover that the building is very different from what the architect intended.

And perception in its general concept is the means by which a person communicates with his environment. He uses his senses to get to know the outside world. And the more the designer is aware of the factors and phenomena that control his perception field, the more clearly, he receives aesthetic messages, and he can influence the viewers, by uniquely linking the basics and elements of the design.

It achieves the greatest degree of harmony between shapes, whether it is flat design work in two dimensions or three-dimensional.

The response is often consistent with the cultures, gender, and demographics of individuals. Accordingly, the designer can produce a design that can stimulate highly anticipated positive reactions on a large scale.

The research has dealt with Gestalt theory and psychology Gestalt, and what is the insight. Then he mentioned in detail the most important principles of Gestalt perception such as (the concept and contrast between the shape and earth, the 
fullness and clarity, the mind fill the gaps, smallness, understanding the whole before recognizing the parts, similarity, proximity, common areas, the whole is greater than the sum of the parts, continuity, and simplicity).

Then the research began to achieve the visual perception of the Gestalt in the mosque building in the following elements (growth, continuity, and hierarchy in the interior design of the mosque, partitioning the spaces of the huge building, treating the facade on several levels, achieving the visual perception of the internal space of the dome, and using the positive and negative to achieve visual perception in building the mosque). The juxtaposition of unlike elements (sensory objects and mental images) enhances the perception of architectural elements.

Also, the perceptual exchange between foreground and background brings sensory pleasure, as well as the common destiny and continuous perceptual exchange between shape and background.

\section{Gestalt Theory}

In the early part of the 20th century, Max Wertheimer published a paper demonstrating that individuals perceived motion in rapidly flickering static images. This belief led to a new movement within the field of psychology known as Gestalt psychology [1].

The Gestalt theory can spark new light when it comes to design. It helps us to think about our compositions in ways that we have not imagined them before. In fact, many principles that come from the Gestalt theory can be applied to all forms of art and design, from painting to photography, digital design to architecture, and good old-fashioned print design [2].

Since its inception early in this century, Gestalt theory has made significant contributions to the study of perception, learning, and social psychology. These contributions remain influential today. Like many important movements in science, Gestalt psychology was born of a revolt against the intellectual establishment of its time. Today several concepts that Gestalt theorists proposed early in this century have been incorporated into the modern understanding of perception, learning, and thought-indeed into our very language and culture [3].

\section{Gestalt Psychology}

The visual pleasure we get from design starts with how we perceive it. And in order to understand how visual pleasure, we must first understand how we perceive visual stimuli.

The human mind is programmed to search for meaning in the visual images that are sent to it. But how does the mind recognize the meanings of shapes and patterns that reach it, or how are visual images perceived.

Gestalt is a German origin word, which means "the complete shape", and it introduces the innate mental laws in which we interpret shapes.

When we see the shape, we do not see or realize its individual parts first, but we see the whole forms before realizing their individual parts. Gestalt theory says 
that "the whole is greater than the sum of its parts" because the whole could not be explained by seeing just the parts of the whole.

And it is like that, like the piece of music, which we do not realize its aesthetic values by playing each instrument on its own, but when all the instruments are played together to form a complete piece of music.

\section{What Is Insight}

The Insight is a human perception of the relationships between things in different situations, reorganize of experience, rebuild ideas, or reformulate the problem.

All of the above includes an understanding of the relationships or an awareness of the relationship between means and objectives to find a solution to the problem.

\section{The Most Important Principles of Gestalt Perception}

The perception has an essential place in gestalt theory, as gestalt theory has provided an explanation for many psychological facts such as memory, innovation, and inference.

\subsection{The Concept of Shape and Ground}

Each perception field has a shape and ground. The shape is more complex than the ground, and the ground is a frame of shape. The words written on the paper are complex, but the (ground) paper is simple. The focus of attention is on the shape more than the ground (the shape attracts attention). We focus our attention on the words written on the paper and not on the paper itself.

Entering changes to the shape is easier than entering it on the ground, so the error in the word written on the paper (the shape) leads to a poor appearance of the paper only, while the error in the paper leads to change it with another. Both shape and ground exist in everything around us, and it depends very heavily on attention, we cannot see the same two at the same time, the sequence of shape and the ground is alternating, and that is the basis of our understanding of things.

\subsection{The Contrast between the Figure and the Ground}

The contrast makes a big difference between shape and ground. This results in poor readability when there is little variation between them-it becomes more difficult for us to distinguish the figure from the ground.

\subsection{Fullness and Clarity}

The Act of full and the psychological reorganization of the situation is intended to be good, complete or full, to the extent permitted by the circumstances of the situation. The fullness achieves understanding and awareness of the relationships in the field between the elements. This depends on the regularity, accuracy, 
and consistency of the elements of the situation. By finding a solution to the problem, the state of cognitive disequilibrium has been removed.

\subsection{Our Mind Fills in the Gaps}

Reification is an aspect of perception in which the perceived object contains more structural information than what is actually present. We try to match whatever we see, to something familiar, which is stored in the memory. But most of the time, there is not an exact match. We then find the nearest match and fill in the gaps in the way we think it should be seen.

Viewers don't need to see the complete outline of the object to perceive it completely. We can leave out parts of the outline when we get a close enough pattern to match [4].

\subsection{Smallness}

Our minds are constantly working to determine the shape and background. Our trend is to know what is small and ignore the big (From a practical point of view). This means that drawing something big isn't usually the way to make it our focal point.

We perceive the color, shape, and size of the object depending on its background. Meaning that the object could be the same size, however, it can be perceived differently if it is presented in a different background. In the design practice, when both the figure and the ground elements are well-defined, it means that the relationship is stable, the figure receives more attention and is better remembered. Moreover, the reader will be able to easily identify the figure without any confusion [5].

\subsection{Understanding the Whole Is Prior to Recognizing the Parts}

During design, after the entire object appears through the outline style, we start to recognize it as a whole. We define the item in its general form first, because the simple, well-defined objects are easily communicable from the detailed objects with the hard-to-recognize perimeter.

\subsection{Similarity}

Our minds can easily choose and group like elements together. But there are different ways that things can look similar. In many cases, our group activity has various ways that objects can be grouped.

The characteristics that can be processed are (size, shape, color, texture, transparency, direction).

Items that are parallel to each other are more related to items that are not parallel to each other. Lines are often interpreted as an introduction, a pointing, or moving in a direction. Parallel lines that indicate or move in the same direction are seen as connected because of this same directional movement.

Items that have a visual connection are linked, while items that do not have a 
connection are not linked.

When similarity occurs, the object can be emphasized more if it is different from other objects. This is called a focal point for a group of elements; it can grab the viewer's attention. Of course, our brains are equipped to identify patterns. If an element diverges from the rest of the surrounding elements, we quickly realize that.

The corresponding structures are satisfactory, but they can be somewhat boring and stable.

Optical symmetry tends to be more dynamic and interesting. Adding an asymmetric shape in symmetric design can help attract attention, it's useful for any focal point, and it is important in any design.

An unexpected finding is that reaction time for asymmetrical complex shapes is shorter than for asymmetrical simple shapes [6].

\subsection{Proximity}

Convergent objects in time and space tend to cluster in integrated cognitive units, unlike objects or units that are apart.

There are four levels basically of the principle of proximity: close, touch, overlap, and annexation. The nearby items seem to be closely related to them. In a group of objects, we often select subgroups of objects that are close to each other. If the elements touch, even if they are different in size and shape, there seems to be a relationship between the objects.

There is a stronger relationship when there is overlap. The exception may be where nested objects seem to create a new, complex shape. Objects may be bound near when they are placed in a larger shape. They are then grouped together in a group that we might call "those elements within the larger shape".

Hence, this principle is considered one of the powerful tools in a design concerning the relatedness. Moreover, it supersedes the similarity of color and shape, as well as, other factors that might differentiate a group of objects [5].

\subsection{Common Regions}

A union can also refer to the relationship of elements that are defined by including elements within other elements, regions, or specific regions. Using borders around a set of elements is a good way to create a distinct separation from other nearby elements.

The principle of a common region can combine many different elements, making it unified in larger groups. It can often be used to bring items to the foreground, indicating an important interaction. We can do this using line, shape, and shadow. The principle of the common area is useful, it can help organize content, it can also achieve region separation or act as a focal point. It reinforces hierarchy, gradation.

\subsection{The Whole Is Greater than the Sum of the Parts}

According to Aristotle, a philosopher in Ancient Greece, "the whole is greater 
than the sum of its parts". This observation was adopted to explain human perception by the Gestalt psychology school of thought in the twentieth century [7].

We think of clear space as a background element, but when we place the elements close to each other on the background, the clear space between the elements transforms into a third individual element. It becomes visually active, whenever the elements are closer together $(1+1=3$ effect $)$. We should study how to position the elements in the background and how much space we have between them.

\subsection{Continuity}

Our minds depend on the continuity in form and direction rather than sudden changes in direction. A continuity break can indicate the end of a section that draws attention to a new piece of content. Continuity helps us interpret direction and motion through the formation. This is done when the elements are aligned and can help our eyes move smoothly across the background, helping to be clear. The principle of continuity reinforces and creates the system, and directs users through different content sectors.

\subsection{Simplicity}

Law of simplicity means that "stimuli are organized in the simplest way possible" both visually and psychologically. According to Gestalt laws of perceptual organization, vast ranges of phenomena in the perceptual organization have been widely interpreted as revealing a preference for simplicity [8].

Therefore, the law of simplicity also refers to the fact that because of the impulsion of harmony and simplified structure in the mind, people may delete the redundant bits of information to highlight the most important ones [8].

\section{Achieving the Visual Perception of Gestalt in the Mosque Building}

\subsection{Growth, Continuity and Hierarchy in the Interior Design of the Mosque}

The designer has distinguished the entrance with its size and plenty of ornaments to celebrate and welcome the worshipers, and also, to introduce awe in their Soul. But after passing the Great High entrance, the visitor found himself in a square room with one of the entrance sides and two of the rest of the sides, each with Ewan, and the third side takes us inside.

This small hall is a stage of transition from the outside world to a spiritual inner world. The visitor leaves the small hall, and heads in, skewed at 90 degrees left toward a narrow and dark corridor.

Then suddenly, he veers right at a 45-degree angle, completely separated from the outside of the entrance, and he sees in front of him only a long, narrow, dark corridor. The corridor is devoid of any decorations or openings. Except, some steps, he rises whenever headway through the corridor. 
We also find some leaked light, from above, through a narrow, skylight, across the corridor, at 37 meters high. Then, the corridor goes back to darkness. Then, after that, a skylight leaks some light, then returns to darkness, and returns to the light. This repeats the situation four times. The corridor ends with a wall, and the visitor suddenly veers at a 90 -degree angle again.

All this is to permanently cut off the visitor from the outside world, and to set him up for a spiritual world, to enter a state of mental clarity for prayer. After the visitor's deviation, he finds a short and dark corridor that ends with a huge door from which strong light leaks.

When he reaches the end of the corridor, he finds himself in front of a majestic scene, a huge open-air patio full of sky and sunlight. The impact of the scene is further enhanced by the fact that the visitor finds him directly in front of him at the end of the courtyard, a huge Ewan height of 38 meters. It is considered one of the largest Ewan in the world, in addition to the other three Ewan, on the rest of the sides of the square courtyard.

Its huge scale, wide space, and high walls emphasize the spiritual feeling of meeting the Greatness of Allah, increasing the sense of humbleness of human beings within God's kingdom (Figure 1(a)). Its existence at the end of the corridor strengthens the tight relationship between the entrance and the prayer hall. Yet, at the same time ensure a smooth transfer between both areas spiritually and physically [9].

\subsection{Verification}

The designer has achieved continuity and hierarchy by dividing the distance from the entrance to the interior courtyard into several stages (a huge entrance, a small square hall located on its sides 2 Ewan, and 2 door openings, a corridor divided into 5 darkness horizontal tube spaces, it is punctuated by 4 illuminated vertical tubular spaces from the sky, and ends with a huge outdoor patio flooded with sunlight) which achieving growth and hierarchy.

The designer thus achieved the psychological preparation of the visitor by using some principles of visual perception of the Gestalt theory, such as growth,

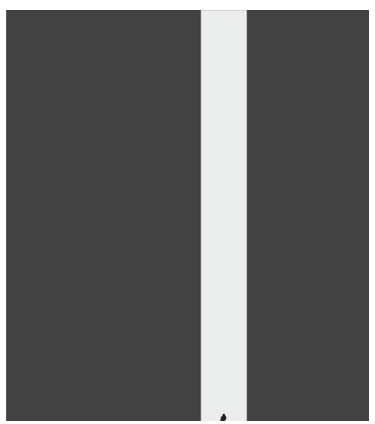

(a)

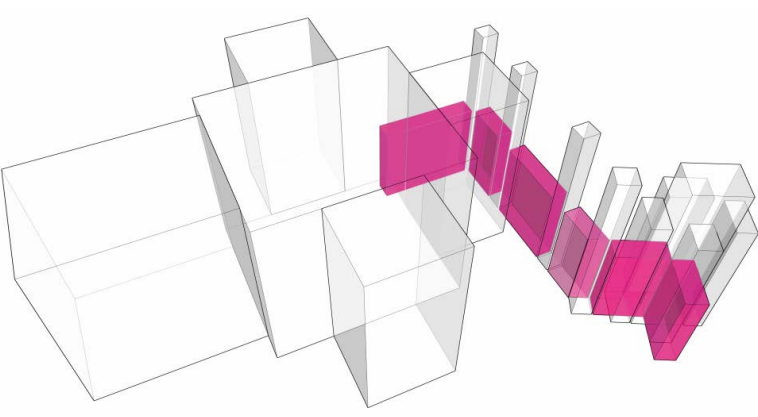

(b)

Figure 1. (a) The ratio of human to space; (b) The designer has achieved continuity and hierarchy by dividing the distance from the entrance to the interior courtyard into several stages. 
continuity, and hierarchy. Design elements now have the ability to grow or connect together to form the integrated design unit (Figure 1(a) and Figure 1(b)).

This mosque is rightly considered the greatest and most sacred Mamluk mosque in the country, it combines the huge building with the Majesty of the architecture.

Hassan Fathy was Believes that despite the huge size of this amazing building, the architectural genius that designed and constructed it shows the obvious combination between the huge dimensions of the building with the human scale. This is done by dividing and distributing the building elements, and logically combining the unity of design and the multiplicity of elements, which should be created when the size increases while maintaining the human scale.

The proposition most often stated as characterizing Gestalt theory, that the whole is more than the sum of its parts, is inaccurate. It is more correct to say, "The whole is something else than the sum of its parts, because summing is a meaningless procedure, whereas the whole-part relationship is meaningful" [10].

What has been achieved in the Sultan Hassan Mosque, is the opposite of what we see (for example) in St. Peter's Church in Rome, whose size has been enlarged without taking into account this division and distribution, making it look like a small building, which we look forward to it through a telescope. The human scale has been absent in that church.

At the west lies of the mosque's main 150-meter facade. On the right side lies the 38-meter-high entrance, which is very large and decorated in stone. The building designed a huge to bring the majesty into the souls of worshippers.

\section{The Layout of the Huge Building Was Divided into Parts}

This mosque was built on the system of schools with orthogonal planning. It consists of four iwans surrounding an open courtyard, the most important and the largest of which is the qibla iwan. And there are four schools among them, to teach the four schools of the Islamic religion. There are four student residences in the schools, consisting of several floors at the height of the mosque, with four open courtyards in the middle (Figure 2(a) and Figure 2(b)).

The same group, consisting of a middle courtyard surrounded by four iwans, was repeated at the entrance to the mosque, but with a smaller size (Figure 3(a) and Figure $3(\mathrm{~b})$ ).

We discover here, that the designer has divided the elements and spaces of the building into parts (mostly into 4 sections-relative to the four doctrines of the Islamic religion), which is preferred when designing the huge buildings.

\subsection{The Designer Has Processed the Facade at Several Levels}

\subsubsection{The First Level}

Perceptual centers interact, first of all, with each other, creating eccentric vectors of action. They, furthermore, interact with frames or formats, which are really larger perceptual centers that serve as frames of reference for these relative elements. Any format can, and often does, become a perceptual center in a larger 


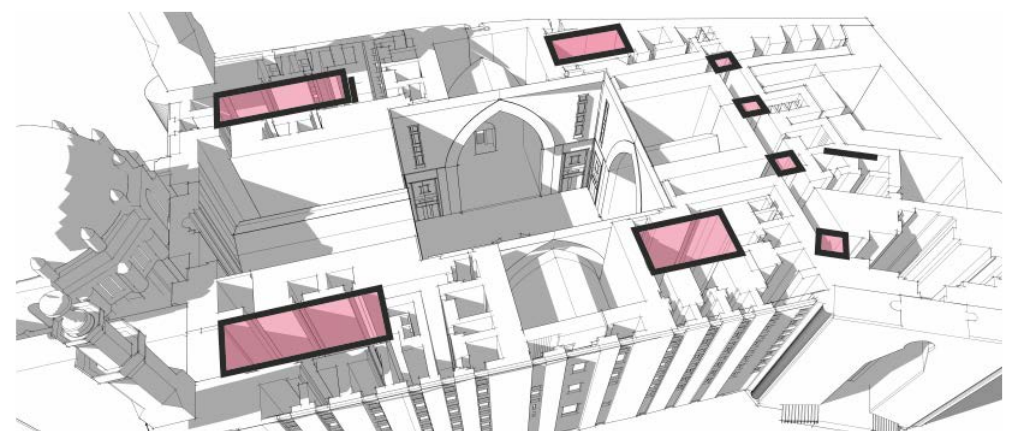

(a)

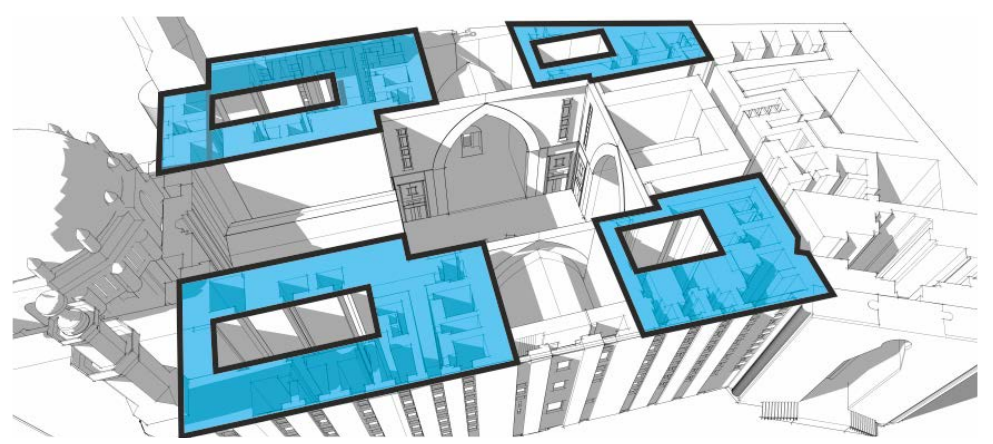

(b)

Figure 2. Four student residences in the schools, consisting of several floors at the height of the mosque, with four open courtyards in the middle.

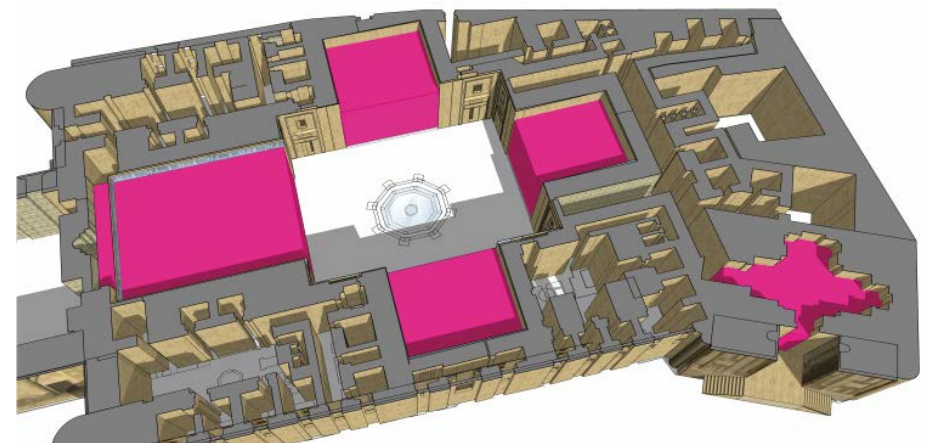

(a)

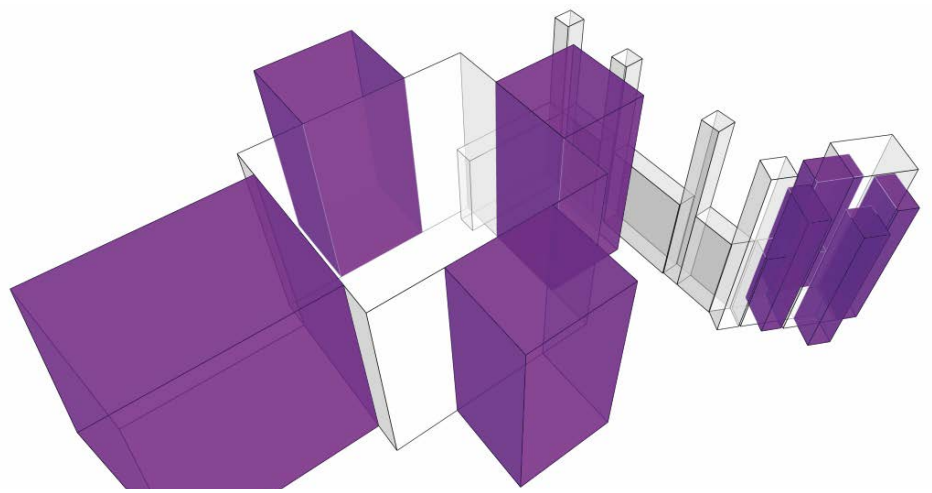

(b)

Figure 3. Group, consisting of a middle courtyard surrounded by four iwans, was repeated at the entrance to the mosque, but with a smaller size. 
frame of reference [11].

The huge facade was divided into three unequal horizontal parts (rectangles). Also, the vertical center axis moved from the center of the facade, as usual in the classic buildings. (This architectural language was later used by Charles René Macintosh at the Glasgow School of Art building). So, the vertical center axis turned into a perceptual center in a larger frame of reference (Figure 4).

\subsubsection{The Second Level}

The first part is divided next to the entrance, to 5 thin vertical rectangles at approximately the full height of the building. And repeat the same rectangles in the third part, but with a larger area, and 7 vertical rectangles. The middle part was a huge, solid and smaller mass in the openings from the other parts, and divided it into three vertical rectangles. The middle of it, is the location of the façade's axis (Figure 5).

\subsubsection{The Third Level}

Vertical rectangles in Part 1 and Part 3 are slightly sunken into the surface of the facade, equal in width and height, but differences in distances between them, divided by 9 different rectangles (windows) in width, and also in height (small and large) alternately, but its size gets smaller as we go up (to optical illusion, and make the viewer see the facade higher than its true size, as the Greeks did in their buildings) (Figure 6).

The middle part, which is wider among all rectangles, is the height of the

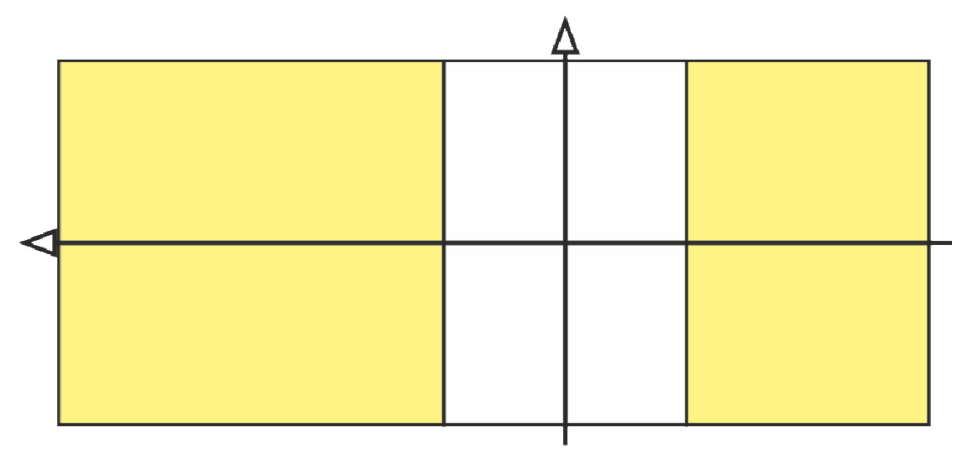

Figure 4. The vertical center axis moved from the center of the facade, as usual in the classic buildings.

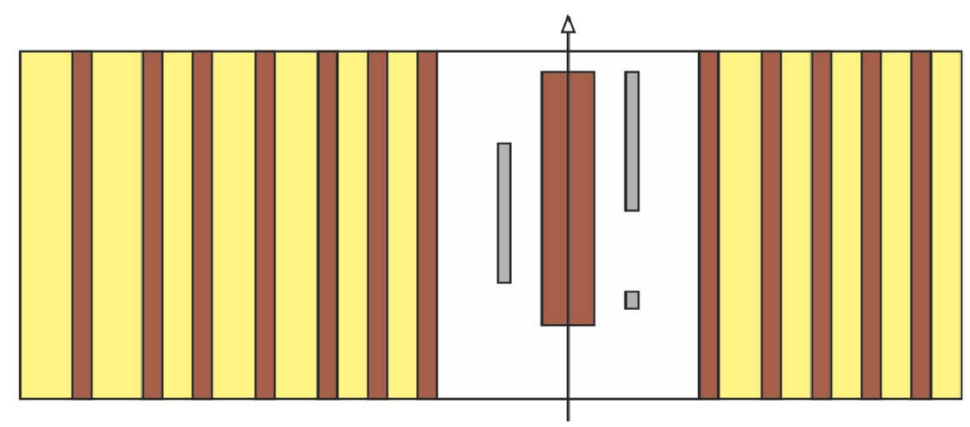

Figure 5. The second level of divided the huge façade. 


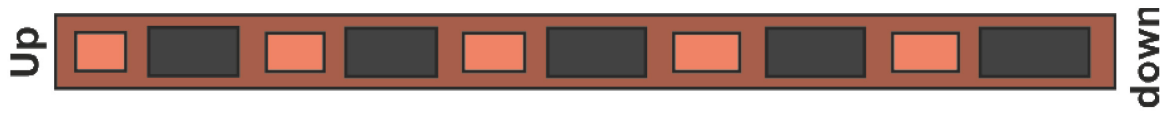

Figure 6. The vertical rectangles (to optical illusion, and make the viewer see the facade higher than its true size, as the Greeks did in their buildings).

whole building. It contains a different language to separate the right part and the left part, and to break down boredom and monotony. Also, it is divided into three rectangles, and the left and right rectangle are less in the middle width. One of them occupies only the upper part, and the other occupies the lower part alternately. Both are significantly different in window size. The middle rectangle is 3 rectangles that are slightly sunken from the surface of the facade and have large windows, the largest of them is the lower, and the size of the windows decreases as we go up (also to deepen the feeling of the large facade) (Figure 7).

\section{Verification:}

Items that share similar properties are seen as more closely related than items that do not share these properties. This principle seems obvious, but has been manipulated in various ways.

When similarity occurs, the most different element can be emphasized. This is called a focal point. This is what happened in the middle rectangle, and it was confirmed by transferring the main axis to it.

The elements are placed close together, the distance between elements becomes an additional individual element that was not already existed, and becomes visually active. This is achieving a theory $(1+1=3)$.

The designer used borders around a group of elements to link the group together and to create a special separation from other elements near it.

The designer used the common destiny act, by placing elements moving together in a vertical direction, to ensure that they are more closely related than fixed or moving elements in different directions. Placing elements in parallel, make them more linked.

He also stressed the vertical orientation to balance the horizontal facade and increase a sense of the building's departure towards the sky.

"For observers susceptible to this illusion the vertical line appears to be longer than the horizontal one." [12].

\subsection{Achieving Visual Perception of the Interior Space of the Dome}

The mausoleum room behind the Qibla wall is a large square room with 21-meter side length, covered by a " 48 " meter high dome and it includes a decorated marble mihrab.

The designer divided the walls of the high dome $(48 \mathrm{~m})$ into several horizontal levels.

The first level is $8 \mathrm{~m}$ high, clad with marble geometric motifs.

Each wall has three openings with pointed arches. In the middle of the wall is a marble panel decorated with floral motifs. Above it is a wooden frame with a width of 2 meters, with gilded and colorful Qur'anic inscriptions. 


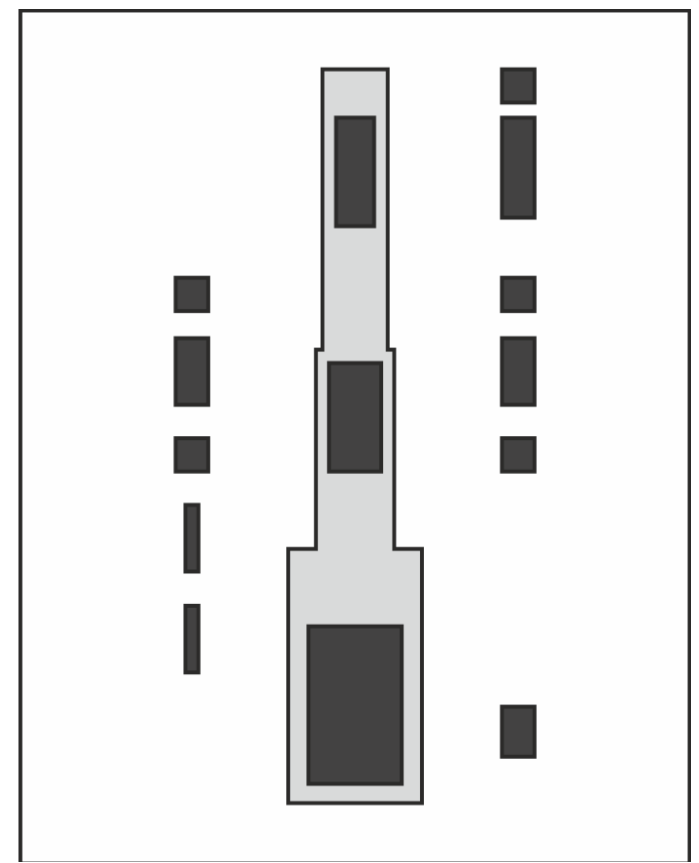

Figure 7. The third level of divided the huge façade.

Then it is followed by an area of 5.80 meters high, occupied by 2 windows in the form of pointed arches in each of the four walls. In the middle of the wall between the two windows, there is a circular window with a diameter of $2.5 \mathrm{~m}$.

The transition areas between the corners of the room and the beginning of the rotation of the dome were treated with muqarnas of colored wood and gilded at an altitude of $11 \mathrm{~m}$ (an architectural element that bridges the space between two levels or transition from a square to a Circle, changing the surface level, and always sees it in the corners under the domes from inside or on minarets under the balconies).

The muqarnas is topped by the neck of the dome and has 8 windows with circular contracts. The body of the dome is devoid of decoration.

The designer divided the area of the large walls into parts, then, divided the parts into smaller units and logically distributed them, that combines the unity of design and the multiplicity of elements, which should arise as size increases, while maintaining human scale (Figure 8).

\subsection{Use the Positive and Negative to Achieving the Visual Perception in the Mosque Building}

Semi-closed or semi-perfect shapes are understood as whole units. Understanding semi-perfect or more closed shapes is easier and faster than open shapes because they tend to create formulas or whole images of shapes.

Our thinking tends to connect points. Where there are gaps. Our minds will tend to group the individual elements that can be connected together to make the shape. Our minds favor explanations that have produced closed objects on open objects. 

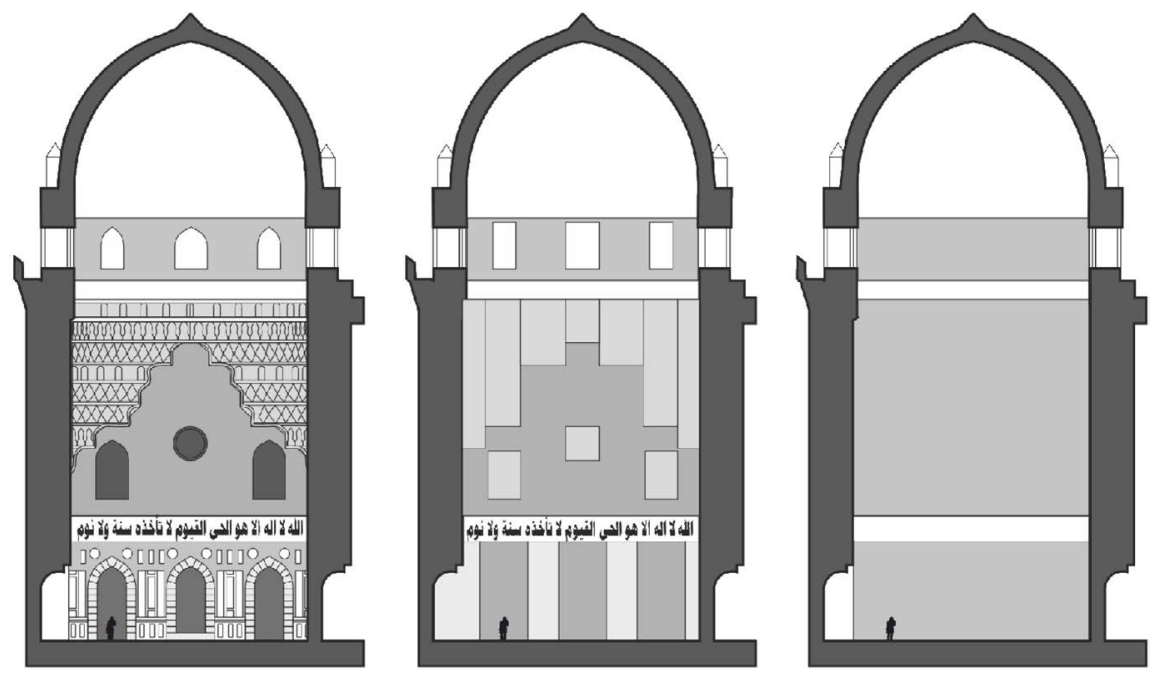

Figure 8. The mausoleum room behind the Qibla wall.

"When you look at objects, they can be defined as either the contour of the object or surface features, like color and brightness. There's been a debate in neuroscience about how this occurs-do you first see the contour and then fill it in like a coloring book, or do you see the surface and from there grow it out to build the contour?"

"Our examination of individual neurons in the visual cortex revealed that the former is true-our brains process the border information first and fill in the surface information second, causing us to perceive something that is in fact not really there." [13]

The mosque's Fence is in the form of a triple plant leaf, a pure geometric shape. It indicates to the connection of the sky to the earth (the building). The sky descends into the building and the interspaces fill between the elements, and marriage between mass and void, negative and positive, or soul and body.

The eye first realizes the shape of the stone Fence (positive), but after checking between the stone elements, the eye begins to recognize the incomplete (negative) shape. The mind starts by completing the missing space. By completing it, we see that it is another different form of a triple flower (Figure 9).

In the wooden pulpit inside the Qibla Iwan, the same idea is found in the crown of the pulpit. But in this case, we find that the positive fence shape is similar to the negative hidden form.

In the wooden pulpit inside the Qibla Iwan, the same idea is found in the pulpit door, where the top of the door opening is surrounded by curved wooden motifs (positive), which creates a decorative shape for the void of the door opening. Whoever sees the pulpit, realizes the woody general form of the pulpit with its decorations, colors, and details. Then, after focusing, realizes the form of the door void between the frame (Figure 10).

In all the walls on the south side, there is a wall work, whose shape varies throughout the day. The designer has created a (positive) a three-dimensional panel, when the sun falls on it, produces black shadows in the shape of triangles, 


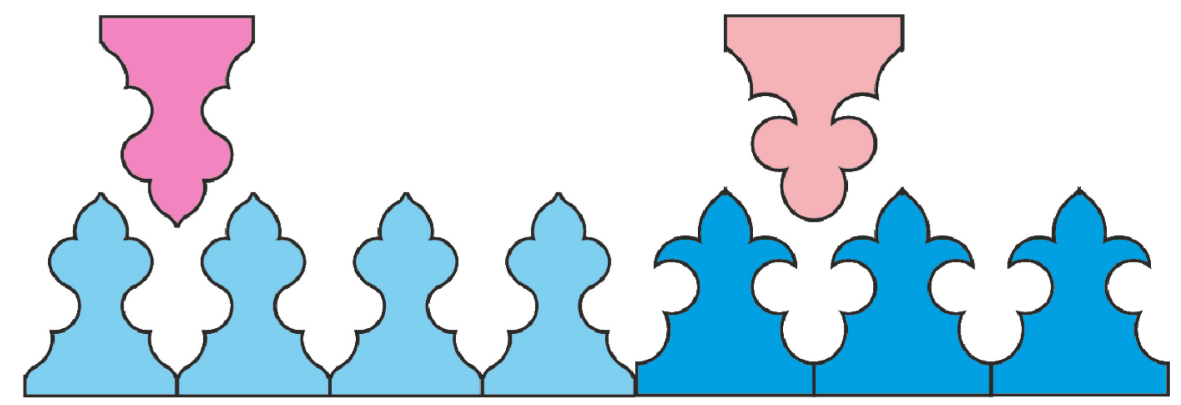

Figure 9. The mosque's fence is in the form of a triple plant leaf.
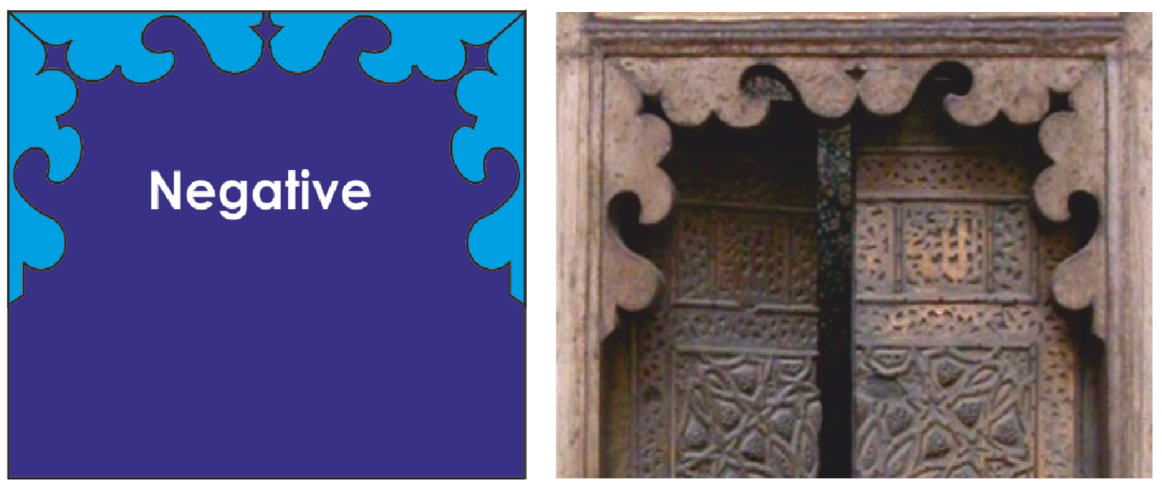

Figure 10. The top of the door, that opening in the wooden pulpit inside the Qibla Iwan.

and converts to diamond shapes (negative), including skewed shapes between them, and a pyramid shape background. The designer has carefully studied the directions of the sun, so this panel is positioned on the south side where sunlight is strong and stays above it as long as possible (Figure 11).

For successful segmentation to occur, the visual system must distinguish veridical object boundaries from internal contours and borders cast by shadows [14].

\subsection{The Juxtaposition of Unalike Elements (Sensory Objects, Mental Images), Enhance the Perception of Architectural Elements}

In the previous cases, first, we understand the positive shape, and then we understand the negative shape. But when we move into the building and get into the middle of the courtyard, we find ourselves first aware of the negative space, but we aware of the positive element after a long time. This is because the negative element (It is the yard space and the four Iwan's spaces) it dominates us strongly for a while, because of the grandeur, power, and magnitude of the space, before we begin to observe the positive element (the solid mass of the building and its details) (Figure 12).

The senses are intelligent in two ways: by posing objects in relationships that reveal productive solutions to difficult problems and by already classifying objects according to abstract principles. In either case, the relationship of elements that promote understanding, derived from an awareness of this relationship, 


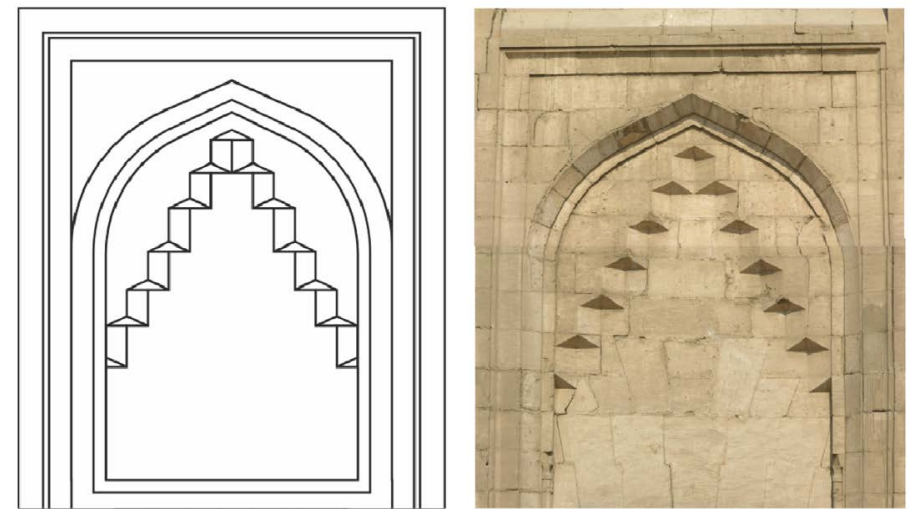

Figure 11. The designer has carefully studied the directions of the sun, so this panel is positioned on the south side.

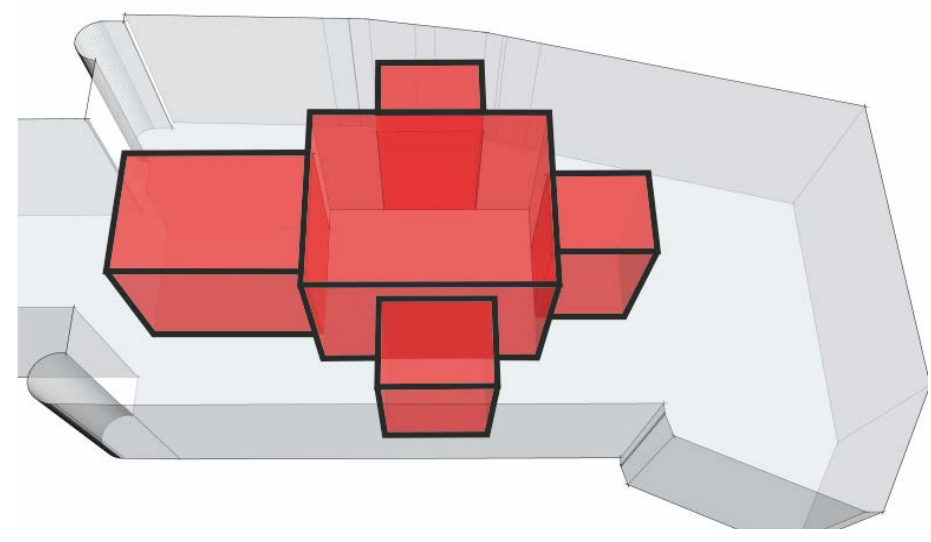

Figure 12. The negative element (it is the yard space and the four Iwan's spaces), and the positive element (the solid mass of the building and its details).

which lies in the juxtaposition of unalike elements (sensory objects, mental images) [11].

\subsection{Perceptual Exchange between Foreground and Back Ground Brings Sensory Pleasure}

The main strip Kufic writing, which is 1.35 meters wide and along the main Iwan walls, 75.00 meters long. It is considered one of the most beautiful Kufic decorative writings in all Islamic architecture. This streak is a graffiti inscribed on the stucco, from the Holy Qur'an, in Kufic script, which is dominated by the geometric characteristic.

The background is of floral motifs, prominent, circular and spiral. The floral motifs of the background are characterized by the endless movement on, which the geometric Kufic writings rest. The letters in the foreground were ascending vertical geometric shapes and horizontal shapes, that reflect the equality between the static and the variable, between movement and stillness, and the contrast between the geometric shape, curved and spiral shape (Figure 13(a) and Figure 13(b)). 


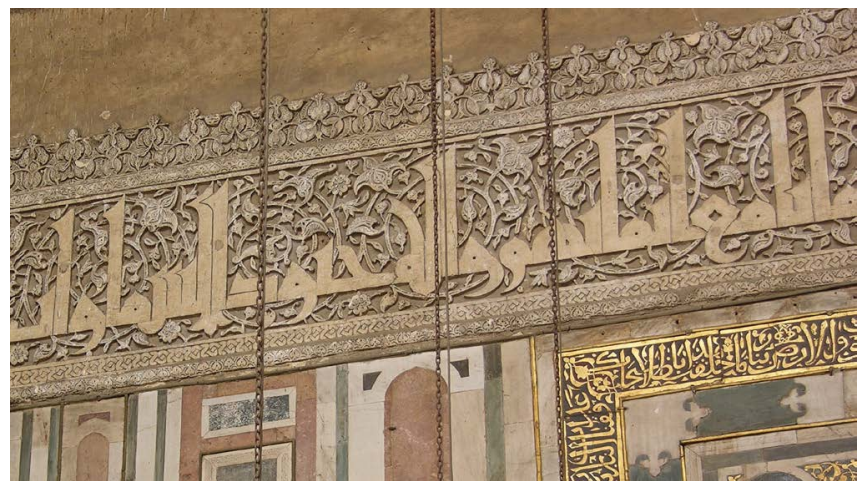

(a)

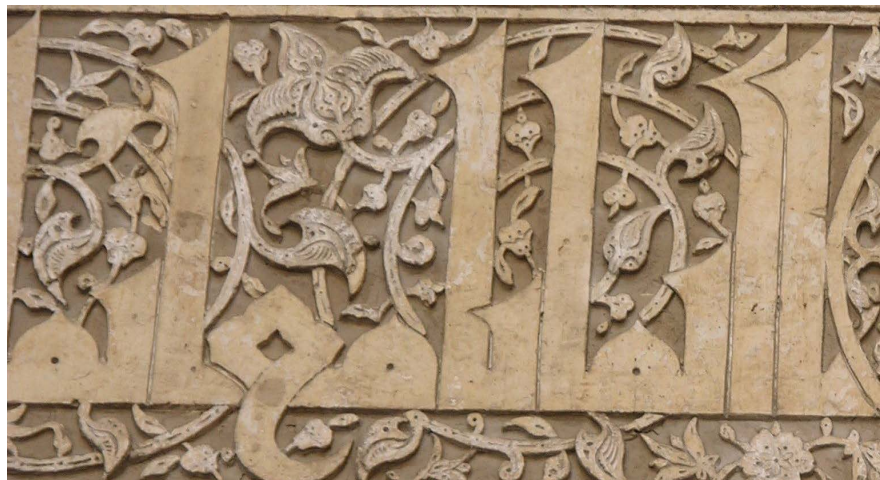

(b)

Figure 13. The main strip Kufic writing along the main Iwan walls. It is considered one of the most beautiful Kufic decorative writings in all Islamic architecture.

\subsection{The Common Destiny, and Continuous Perceptual Exchange between Shape and Background}

The principle of the common destiny of the shapes, that share a movement in the same space, and at the same time, realize as belonging to the same group. The mind tends to perceive it as one entity.

According to the principle of continuity, a human being tends to perceive any complex shape as having connected lines and patterns. When a design is composed of straight lines that cross other lines in a different direction, it looks like an extended even cut the line.

The ornaments at the Sultan Hassan Mosque are rich in designs based on overlapping interlocking lines, in a visual design that stretches in multiple directions, but they realize it is connected.

The ornaments of the star dish in the Holy Qur'an chair, and in the copper doors, consist of strips and a background. The shape and the ground are equally important, and a continuous perceptual exchange takes place between shape and background.

We may see the shape (stripes) as a case once, and the background as a shape in another time, as a result of the continuous perceptual exchange process between the shape and the background, each having its own attraction (Figure 14). 

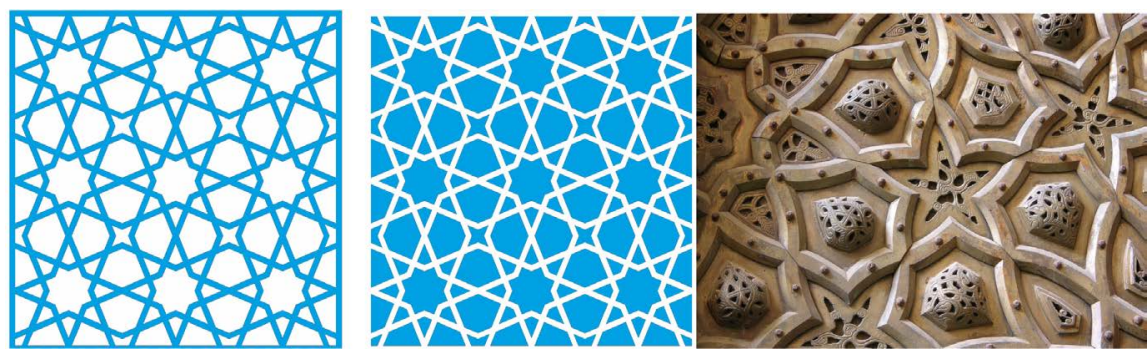

Figure 14. The ornaments of the star dish in the Holy Qur'an chair, and in the copper doors.

Experience has an important role to play in the perception process, the so-called perception development. Perception growth is a process with which the perception recognized elements are obtained from various interconnections through experience.

The theory is primarily aimed at creating a positive overall impression. Everything is somehow designed, capable of producing a certain passion, followed by emotional reactions a moment after time.

Therefore, Architecture must not only seek to design usable buildings, but also generate a psychological impact on users' brains and feelings.

\section{Conclusions}

There are those who neglect the plastic aspect in the mosques and consider it only an external crust that does not affect its function and mission. Sultan Hassan Mosque is one of the buildings that exceed the traditional architectural restrictions through symbolic and functional meanings.

Incorporating the principles of visual perception of gestalt theory into design work can greatly improve the experience, as we saw in the Sultan Hassan Mosque. Especially since the principles of gestalt confirm that the human brain tends to make tricks and illusions. Therefore, we found the mosque designer had exploited this fact during the design process, to exclude any possibility of the resulting misunderstanding.

Through the Gestalt theory, the designer seeks to create unity and complementarity within a single design. The stronger the relationship between the design elements, the better the designer will communicate and communicate with the recipient. This theory also helps the designer influence the viewer by controlling how the design is presented.

The designer achieved the psychological preparation of the visitor by using some principles of visual perception of the Gestalt theory, such as growth, continuity, and hierarchy. Design elements now have the ability to grow or connect together to form the integrated design unit.

The huge size of this amazing building, and the architectural genius that designed and constructed it, and the obvious combination between the huge dimensions of the building with the human scale, are done by dividing and distributing the building elements, and logically combining the unity of design and 
the multiplicity of elements, which should be created when the size increases while maintaining the human scale.

For successful segmentation to occur, the visual system must distinguish veridical object boundaries from internal contours and borders cast by shadows.

The senses are intelligent in two ways, by posing objects in relationships that reveal productive solutions to difficult problems, and by already classifying objects according to abstract principles. In either case, the relationship of elements that promote under-standing derived from the cognition of this relationship reveals expression, which lies in the juxtaposition of unalike elements (sensory objects, mental images).

We may see the shape as a case once, and the background as a shape in another time, as a result of the continuous perceptual exchange process between the shape and the background, each having its own attraction.

\section{Conflicts of Interest}

The author declares that there is no conflict of interest regarding the publication of this manuscript.

\section{References}

[1] Gestalt Principles of Perception (2019).

https://courses.lumenlearning.com/waymaker-psychology/chapter/gestalt-principle s-of-perception/

[2] Graybox, A. (2020) Gestalt Principles Applied to Design. https://graybox.co/knowledge/blog/gestalt-principles-applied-to-design

[3] Rock, I. and Palmer, S. (2020) The Legacy of Gestalt Psychology. Scientific American, 263, 84-91.

https://newschoolhistories.org/wp-content/uploads/2019/02/gestalt.pdf https://doi.org/10.1038/scientificamerican1290-84

[4] Garg, C. (2019) Principles of Design, Visual, Perception and Gestaltism. https://medium.com/@charchitgarg27/principles-of-design-visual-perception-andgestaltism-2b0c4206834a

[5] Gad, D. (2018) Information Design of Public Documents: Applying Gestalt Principles to Improve User Understanding.

[6] Marija, M., Marković, S. and Gvozdenović, V. (2012) Role of Symmetry and Simplicity in Shape Disruption Perception Tasks. Psihologija, 45, 5-22. https://doi.org/10.2298/PSI1201005M

[7] Halimi, O., Imanuel, I., Litany, O., Kimmel, R., Trappolini, G. and Rodolà, E. (2020) The Whole Is Greater Than the Sum of Its Nonrigid Parts. arXiv:2001.09650 [cs.CV]

[8] Zhao, Y.S., Xu, L. and Lü, L.Q. (2016) The Application of Gestalt Simplicity Principle in Translation of Charlotte's Web. Studies in Literature and Language, 12, 14-18. http://www.cscanada.net/index.php/sll/article/view/8117

[9] Ismail, K. (2010) Sultan Hassan Mosque: An Islamic Architectural Wonder Analytical Study of Design and Its Effect on Islamic CAIRO. Journal of Islamic Architecture, 1, 94-105.

[10] Wagemans, J., et al. (2012) A Century of Gestalt Psychology in Visual Perception: 
II. Conceptual and Theoretical Foundations. Psychological Bulletin, 138, 1218-1252. https://doi.org/10.1037/a0029334

[11] Verstegen, I. (2005) Arnheim, Gestalt and Art: A Psychological Theory. SpringerWien, New York.

[12] Cenek, J. and Šašinka, Č. (2015) Cross-Cultural Differences in Visual Perception. Journal of Education Culture and Society, 2015, 187-206. https://doi.org/10.15503/jecs20151.187.206

[13] Vanderbilt University (2007) The Brain Doesn't Like Visual Gaps and Fills Them In. https://www.sciencedaily.com/releases/2007/08/070820135833.htm

[14] Pasupathy, A., et al. (2018) Visual Shape and Object Perception. Journal of Neuroscience, 20, 8188-8198. https://doi.org/10.1093/acrefore/9780190264086.013.75 